\title{
Porosity properties of porous ceramic substrates added with zinc and magnesium material
}

\author{
D. Bouras ${ }^{\mathrm{a}}$, A. Mecif ${ }^{\mathrm{a}}$, R. Barilléb ${ }^{\mathrm{b}}$, A. Harabi ${ }^{\mathrm{c}}$ and M. Zaabat $^{\mathrm{a}}$ \\ ${ }^{a}$ Laboratory of Active Components and Materials, Larbi Ben M'Hidi University, Oum El \\ Bouaghi 04000, Algeria. \\ b'MOLTECH-Anjou, Université d'Angers/UMR CNRS 6200, 2 Bd Lavoisier, 49045 Angers, \\ France. \\ ${ }^{\mathrm{c} C e r a m i c s ~ L a b o r a t o r y, ~ M e n t o u r i ~ U n i v e r s i t y, ~ C o n s t a n t i n e ~ 25000, ~ A l g e r i a . ~}$
}

\begin{abstract}
Ceramic based materials covered with a mixture of mullite and zircon on the top, strengthened by the addition of zinc and magnesium compounds at different rates ( $37 \%$ and $50 \%$ ) and made by a co-precipitation method are studied. The thermally treated and shaped materials prepared in the shape of cylindrical samples were modified to obtain different porosities. The addition of zinc to the ceramic based material leads to a significant increase and control of the density of porosity compared to the addition of magnesium. The porosity of all the materials was characterized. The permeability characteristics and the ability for all the pellets to absorb water until the saturation were also studied as a function of the porosity.
\end{abstract}

Keywords: Mullite-Zircon; Zn/Mg; porous material; ceramic clay; Diffusion of drop.

\section{Introduction}

The development of new microporous ceramic membranes [1 - 4] for nanofiltration [5 - 6], ultrafiltration [7 - 8] and microfiltration [9 - 10] have been studied since several years in the goal to obtain cheaper finished products. The use of organic membranes is currently more developed, but in some specified applications ceramic membranes have a number of advantages, such as a better mechanical, thermal and chemical resistance [11].

Porous ceramics have found many interests and can be used as membranes, filters, catalyst supports, heat exchangers, supports for bone regeneration, sensors, thermal insulators in construction or in aerospace applications, flue gas burners and lightweight materials for construction [12-14]. Membranes on the other hand are used in clarification and concentration 
operations in various fields such as: agribusiness, biotechnology, pharmacy, water and effluent treatment. Membrane processes are often economically competitive compared to traditional processes and may also contribute to the improvement of other process-coupled separation techniques [15].

The originality of this present work lies in the use of an inexpensive and abundant material for the membrane fabrication. The basic component is obtained from a local Algerian region of the north-east of Algeria (Guelma). The material is composed of Kaolinite and halloysite and is rich of Alumine. The ceramic material is processed with mullite and zircon and mixed with or without the addition of zirconia, after an adequate heat treatment at $1200^{\circ} \mathrm{C}$ [16-17].

Moreover, in order to increase the material absorption or permeability by controlling pore diameters, other compounds were added to the ceramic based material. Magnesium and Zinc were chosen for mixing materials. We have found that in most of the time, the absorption of the overlapping material is larger than the unsupported ceramic material, especially at high temperatures [18 - 19]. In this work, the pellets are made with prepared modified ceramics and tested with distillate water $\left(\mathrm{H}_{2} \mathrm{O}\right)$ in order to study the liquid permeability.

In the case of our mixed materials, it was observed that the degradation of the material based on zinc and magnesium break the inter-linkages between the ceramic powders and creates a porosity on the surface and inside the material. In order to understand the influence of the porous structure on transport phenomena in the case of environmental applications for example, it is essential to find appropriate ways to quantitatively measure/describe the porous structuration. We used different characteristics (porosity, connectivity, ...) that lead to obtain critical parameters able to characterize porous structures often employed in the description of many transport phenomena, such as water transmission [21].

Thus, the present study is focused on the characterization of the modified porous kaolin based on ceramic materials (DD3) and on how a liquid can diffuse into the mixed materials. We used water in the experiment in order to describe the permeability phenomenon in the different samples considering their inner structural characteristics.

\section{Materials and methods}

\subsection{Materials}

In order to prepare the studied pellets, the mullite-zircon components were made with a primary local kaolin clay-based material (DD3) obtained from the region of Guelma (Djebel Debagh) in Algeria and supplies by ETER (ceramic company in Guelma, Algeria). The crystallographic 
structure of kaolinite belongs to the $\mathrm{C} 1$ space group. Two types of hydroxyl groups are bonded to the octahedral Al cation: (1) the inner surface hydroxyls, which interact with the siloxane groups of an adjacent layer; and (2) the inner hydroxyl $\mathrm{O}-\mathrm{H}$ bonds, which are parallel to the layer. The kaolinite structure is highly asymmetric, which results in strong dipolar interactions between the layers. The raw kaolin is rich in $\mathrm{SiO}_{2}(42 \%)$, in $\mathrm{Al}_{2} \mathrm{O}_{3}(38 \%)$ and contained only small amounts of $\mathrm{Fe}_{2} \mathrm{O}_{3}, \mathrm{MgO}, \mathrm{CaO}$, and $\mathrm{MnO}$. The ratio $\mathrm{SiO}_{2} / \mathrm{Al}_{2} \mathrm{O}_{3}$ confirms that this material is close to a pure halloysite [22]. The ceramic-based material is mixed with the addition of $38 \%$ of zirconium oxide $\left(\mathrm{ZrO}_{2} ; 99.5 \%\right.$ purity). Zinc acetate $\left(\left(\mathrm{CH}_{3} \mathrm{COO}\right)_{2} \mathrm{Zn} 2 \mathrm{H}_{2} \mathrm{O} ; 99.5 \%\right.$ purity) and magnesium acetate $\left(\mathrm{Mg}\left(\mathrm{CH}_{3} \mathrm{COO}\right)_{2} 4 \mathrm{H}_{2} \mathrm{O} ; 99.5 \%\right)$ were used as additives to these components. Sodium hydroxide $(\mathrm{NaOH} ; 96 \%$ purity) was used as a solvent.

The effectiveness of these substrates and their absorbability has been controlled by choosing water.

\subsection{Preparation of powders and substrates}

The DD3 $+38 \% \mathrm{ZrO}_{2}$ powder was treated at a temperature of $1200^{\circ} \mathrm{C}$ after grinding and sieving. The obtained ceramic powder was a composite of millite-zircon (called DD3Z) after this thermal transformation.

The ceramic powders were prepared with additives. The co-precipitation method was applied [23] where different percentages of zinc acetate (37\% and 50\%) (DD3Z(t) $+37 \% \mathrm{ZnO}, \mathrm{DD} 3 \mathrm{Z}(\mathrm{t})$ $+50 \% \mathrm{ZnO})$ and magnesium acetate $(50 \%)(\mathrm{DD} 3 \mathrm{Z}(\mathrm{t})+50 \% \mathrm{Mg})$ were added to the previous mentioned powder. The percentages of $\mathrm{ZnO}$ or $\mathrm{Mg}$ result in the calculation of percentage of additional compounds considering the reference mass of DD3Z(t) (100\%). Different masses of $\mathrm{Zn}$ and $\mathrm{Mg}$ where used $(3 \mathrm{~g}, 2 \mathrm{~g}, 1 \mathrm{~g}, 0.5 \mathrm{~g}$ ) referred in percentage as a function of DD3Z and optimized for finally obtaining the final studied powders.

These elements were dissolved in the presence of $\mathrm{NaOH}$ and well mixed with distilled water (3 $\mathrm{g}$ in $100 \mathrm{ml}$ ), and then treated at $500{ }^{\circ} \mathrm{C}$.

Cylindrical pellets were prepared based on $1 \mathrm{~g}$ of this powder without and with different additives using a $20 \mathrm{~mm}$ matrix and a hydraulic press ( 0.5 tons). These samples were treated at $1000{ }^{\circ} \mathrm{C}$ for two hours to improve the hardness and compacticity. The figure 1 illustrates the used procedure for the sample fabrication and shows the fabricated pellets. The pellets have a thickness of 4.5, 3.4, 5.0 and $4.0 \mathrm{~mm}$ and a diameter of 19.8, 17.3, 20.1 and $17.2 \mathrm{~mm}$ for $\mathrm{DD} 3 \mathrm{Z}(\mathrm{t}), \mathrm{DD} 3 \mathrm{Z}(\mathrm{t})+37 \% \mathrm{ZnO}, \mathrm{DD} 3 \mathrm{Z}(\mathrm{t})+50 \% \mathrm{ZnO}, \mathrm{DD} 3 \mathrm{Z}(\mathrm{t})+50 \% \mathrm{Mg}$ respectively. The sample DD3Z(t) $+37 \% \mathrm{Mg}$ was not considered in the study because a preliminary test with a 
droplet of water put on the surface of the fabricated pellet showed the liquid stayed on the surface and was unable to penetrate and flow through the material with the same range of time. The study was then focused on these four materials.

\subsection{Characterization techniques}

The structural analysis of the ceramic substrates obtained from $\mathrm{DD} 3+\mathrm{ZrO}_{2}$ after treatment at $1200^{\circ} \mathrm{C}$ with and without addition of $\mathrm{Zn}$ and $\mathrm{Mg}$ is carried out by XRD. The patterns recorded on all the samples are shown in the figure 2. A previous study [24] has shown the mineralogical and chemical characteristics, based on X-ray diffraction (XRD) of a kaolin raw known as DD3, from eastern Algeria. From this figure, one can notice that the most intense peaks are obviously those of the ceramic phases; tetragonal zircon (JCPDS 06-0266), monoclinic zirconia (JCPDS 37-1484), orthorhombic mullite (JCPDS 15-0776) and cubic cristobalite (JCPDS 01-0424) and are dominant in the patterns for the substrate DD3Z $(\mathrm{t})$. The heat treatment allows the formation of the zircon by consumption of $\mathrm{SiO}_{2}$ (cristobalite) which reacts with zirconia to create micropores. After addition of the $37 \% \mathrm{ZnO}$ and $50 \% \mathrm{ZnO}$, there are minor peaks appearing at $31.83^{\circ}$, $34.54^{\circ}$ and $36.32^{\circ}$. This latter corresponds to the (100), (002) and (101) planes of the $\mathrm{ZnO}$ wurtzite phase (JCPDS 03-0891), respectively. However, the big amount of Mg used in the DD3Z $(\mathrm{t})+50 \% \mathrm{Mg}$ substrate is not detected. We observe a noticeable disappearance of $\mathrm{ZrSiO}_{4}$ with the significant addition of $50 \%$ magnesium at the high temperature of $1000^{\circ} \mathrm{C}$, this can be explained by the interaction between these two latter $\mathrm{ZrSiO} 4$ and $\mathrm{Mg}$, which leads to the disappearance of magnesium and the absence of any phases with emergence of their glass phase.

The characterization of the sample porosity was done with a scanning electron microscope (SEM) (JSM-6301F) by analyzing the different external surface zones of the sample and by acquiring bulk informations of the samples. A surface and transverse characterization were done. For the last characterization, the pellets were cut vertically at different positions. We then acquired images of the sample surface at different locations inside the pellets giving crosssection images. The SEM pictures allow characterizing coordination numbers or the pore connectivity and average throat lengths. The average and the relative standard deviation of the pore radius were calculated.

However, before the pore-size characterization with an image processing software, the SEM images have to be pre-processed. A thresholding procedure must be done to obtain black and white binary images. For the connected pore calculation, it is necessary to find boundaries 
between pores (separate connected voids) using a suitable segmentation algorithm. We used an image processing software (Matlab) to transform the image in black and white and to threshold the intensity in order to evaluate the black region corresponding to a pore.

The used algorithm for determining the pore and network characteristics consists in morphological operations (closing, opening) and thresholding of the resulting SEM images. The aim is to separate the monolithic void structure of the sample into specific pores and throats connecting to each other. Initially, two connected objects should be separated by these image processing algorithms. We used the watershed segmentation [25, 26]. The basic image corresponding to this technique is the one of a drop of water falling on a topographic relief flows towards the "nearest" minimum. Watershed provides a fast and efficient method for segmentation and separation of attached clusters of objects. So, the different steps are: image binarization, noise filtering, watershed segmentation, labelling and connectivity analysis and finally building local pore networks.

The coordination number is also called pore connectivity and shows how each pore is connected to what number of adjacent pores [27 - 28]. This parameter is a key to find the relationship between porosity and permeability of porous media.

The coordination number or connectivity of a pore network is easily obtained by analyzing the abutting pores and throats and counting the number of throats connected to each pore [29]. Basically, the coordination number is defined as the number of pore throats connected to a single pore. The pore connectivity is one of the most important parameters determining the hydraulic characteristics of the porous medium. Not-interconnected porous martial has no permeability and vice versa. This parameter is a fundamental characteristic of pore networks and has a noticeable impact on hydraulic conductance of porous rocks.

The calculation of the porosity ratio is the fraction of the total ceramic volume that is taken up by the pore space. Thus, it is a single-value quantification of the amount of space available to fluid within a specific body of porous material. The porosity is simply a fraction of the total volume, and can range between 0 and 1, typically falling between 0.3 and 0.7 for soils.

The image analysis was performed with the Matlab software and therefore it was possible to use functions of the image processing toolbox to obtain the porosity characteristics.

The time required for the spread of the liquid from the top to the bottom of the sample was measured using a CCD camera (IDS $\mu$ Eye) with a magnification of $100 \mathrm{X}$ and image acquisition software (fig. 3). A movie was recorded. In order to characterize the liquid diffusion into the porous material, the movie was sequentially analyzed image per image with Matlab. A pipette (Thermo fisher) with a variable volume and a single channel was used to deliver a droplet on 
the top of the pellet. A custom-made sample holder was used to mount the pellets directly beneath the CCD camera. The cross-section images of the liquid penetrating into the bulk were done by cleaving the pellet with a ceramic knife.

\section{Results and discussion}

\subsection{Characterization of the samples}

The main objective of the sample analysis with the SEM was to characterize the porous material and to analyze the zones on the pellet where the pores are distributed. The degree of porosity of the ceramic pellet types was determined by calculating the pore diameters and connections. We choose to focus our calculations at the center of the pellets. A comparison with same calculations done at the edge of the samples has shown similar results for all the chosen characteristic parameters.

The figure 4 presents SEM observations of the surface and the porosity calculation. The white surfaces correspond to pores. The figure 4 shows clearly the difference between the four samples and the role played by the zinc and the magnesium to the differences in the microstructures of the ceramic material and the influence on the control of the porosity characteristics. We note that the surface and the different cross-sections of the pellets show similar characteristics. The distribution of the pore radiuses is presented in the figure 5 . The pore radiuses are larger for DD3Z(t) $+50 \% \mathrm{ZnO}$ compared to DD3Z(t) and decrease with the reduction of $\mathrm{Zn}$ or the addition of $\mathrm{Mg}$. The average pore diameter is $71 \mathrm{~nm}$ in the presence of $50 \%$ of zinc while it reaches $46 \mathrm{~nm}$ after the addition of the same percentage of magnesium. The addition of $50 \% \mathrm{Mg}$ reduces the number of pores and decreases the diameter. The difference between the center and the edge of the pellet is weak less than $2 \%$. The minimum distance between the pore is $1.1 \mathrm{~mm} \pm 0.2 \mathrm{~mm}$. For all the samples the calculated distance between the centroïd of the pores is similar. So, the pore radius is changed with the addition of $\mathrm{Mg}$ or $\mathrm{ZnO}$ and these compounds do not allow an increase of the porosity except for a high doping of $\mathrm{ZnO}(50 \% \mathrm{ZnO})$ because these two compounds were sufficiently effective to change the morphology of the sample contrary to samples without addition (DD3Z) or even in the case of a few additions of these compounds $(<50 \% \mathrm{ZnO})$. The results confirm the densification nature of $\mathrm{ZnO}$ for modifying the porous material by increasing the pore radius ( $\mathrm{x} 1.3$ ) and reducing the porosity (x 0.8$)$. However, $\mathrm{Mg}$ with a low density $(<50 \%)$ does not influence the morphology as far the experiment with a simple drop of water on the surface demonstrated it but reduces the porosity and pore radius with a high density (50\%). 
This result is also confirmed with the calculation of the chord length distribution. The chord length distribution (CLD) gives the probability of having a chord length between $r$ and $r+d r$ where $\mathrm{r}$ and $d r$ represent the interface between the pore and the solid phase. For the pure sample without addition of $\mathrm{Zn}$ or $\mathrm{Mg}$ the distribution of chord lengths is broad compared to other samples. $\mathrm{DD} 3 \mathrm{Z}(\mathrm{t})+50 \% \mathrm{ZnO}$ has the minimum number of chord lengths. The CLD value is similar between DD3Z(t) and DD3Z(t) $+50 \% \mathrm{ZnO}$ but the width is reduced for DD3Z(t) + $37 \% \mathrm{ZnO}$ and comparable in distribution with $\mathrm{DD} 3 \mathrm{Z}(\mathrm{t})+50 \% \mathrm{Mg}$. We can conclude that a weak quantity of $\mathrm{ZnO}$ doping or $\mathrm{Mg}$ do not affect the chord length.

The average grain is larger for DD3Z(t) $+50 \% \mathrm{ZnO}$. In this case we observe that DD3Z(t) + $50 \% \mathrm{ZnO}$ with the maximum grain size has also the maximum pore radius. The addition of $\mathrm{ZnO}$ increases the grain size and the pore radius of the sample. Inversely, the average grain size and pore radius values are reduced with $\mathrm{Mg}$.

The porosity ratio is $0.2,0.18,0.26$ and 0.16 for the DD3Z(t), DD3Z(t) $+37 \% \mathrm{ZnO}, \mathrm{DD} 3 \mathrm{Z}(\mathrm{t})$ $+50 \% \mathrm{ZnO}$ and DD3Z(t) $+50 \% \mathrm{Mg}$ samples respectively. The porosity ratio is then similar for all the four samples except for DD3Z(t) $+50 \% \mathrm{ZnO}$ where the size of the pores is the maximum. This last different value for the pore size is due to the initial state of overlapping materials of ceramic powder and zinc, where it was found that the decomposition of zinc at high temperatures works to break the inter-linkages between the ceramic powders and creates spaces on the surface of the sample and inside [30].

The pore coordination number refers to the segmented representation of the pore space and measures the number of pores with which a given pore shares throat vowels. The connectivity increases with the size of pore throats and with the increasing number of pore throats surrounding each pore. The number of pore throats that is connected with each pore is the coordination number. The throat number for all the samples is evaluated in the goal to have a knowledge of the connectivity of the pores for all the samples (fig. 6). The throats surrounding each pore have been calculated. $\mathrm{DD} 3 \mathrm{Z}(\mathrm{t})+50 \% \mathrm{ZnO}$ has the best connectivity of the pores. In this material each pore is linked to 5 throats. $\mathrm{DD} 3 \mathrm{Z}(\mathrm{t})+50 \% \mathrm{ZnO}$ has the minimum connections to throats. So, for this material there is a compromise between large pore radiuses and low connectivity. DD3Z(t) $+50 \% \mathrm{Mg}$ has the smallest pore radius but the best connectivity. The average throat radius is maximum for $\mathrm{DD} 3 \mathrm{Z}(\mathrm{t})+50 \% \mathrm{Mg}(1050 \mathrm{~nm})$ and minimum for both $\mathrm{DD} 3 \mathrm{Z}(\mathrm{t})+50 \% \mathrm{ZnO}$ and DD3Z(t) $(702 \mathrm{~nm})$. The connectivity, the pore throats and the pore diameter act on the permeability of the material. This permeability is a fundamental characteristic of pore networks and has a noticeable impact on hydraulic conductance of porous 
ceramics. The figure 6 represents for the four samples the topologically networks that realistically represents the pore connected by the pore throats. The pore and throat scale network modeling can predict multiphase flow properties with the wetting condition. The permeability and capillary pressure functions define the flow behavior in the four porous media. These two parameters critically depend on the geometry and topology of the pore space, the physical relationship between ceramic grains and the fluids. The permeability $\mathrm{K}$ is a measure of how easily fluids can flow through a given porous material and can be approximated with the equation $[31,32]$ :

$$
\mathrm{K}=\mathrm{Cr}^{2}
$$

However, empirically the permeability has been described by the following equation:

$$
\log (\mathrm{K})=\mathrm{a} \cdot \varphi^{\mathrm{b}} \cdot \mathrm{N}_{2 \mathrm{D}}^{\mathrm{c}}+\mathrm{d}
$$

in which $\mathrm{a}, \mathrm{b}, \mathrm{c}$, and $\mathrm{d}$ are empirical constants, $\mathrm{K}$ is absolute permeability (md), $\varphi$ is the experimental porosity and $\mathrm{N}_{2 D}$ is the average 2-D coordination number obtained from the image analysis. Porosity and average 2D coordination numbers are efficient parameters for predicting the permeability of carbonates [33] and can also be used for predicting the permeability of the DD3Z(t) material and doped DD3Z(t) considering the influence of the two main parameters. Based on the previous characterizing parameters obtain with the 2D SEM observations we can predict qualitatively the permeability of each sample. We observe that $\mathrm{DD} 3 \mathrm{Z}(\mathrm{t})+50 \% \mathrm{Mg}$ has the minimum porosity ratio but the maximum coordination number and maximum throat length. The pore radius is also the minimum among all the samples. So, this material should have a good permeability. DD3Z(t) $+50 \% \mathrm{ZnO}$ is the opposite situation with the maximum of pore radius and porosity but an average coordination number and throat number very small. We observe also that for this material the chord length distribution was very broad, and all the different sizes of pore radius can be found in this material.

\subsection{Liquid saturation of the pellets}

In order to determine the ability of these samples to absorb liquids and to determine the time required to reach the saturation level of the filtration inside the sample we have used the experimental set-up with a CCD camera presented in the figure 3 to monitor the backside of the 
sample and the cross-section. This experiment of liquid transport in doped ceramic materials combines the characteristics of pore diameter, pore density and pore connectivity.

Water was used in the experiment as a simple reference liquid with a low viscosity able to test the permeability of the materials. In a first experiment, successive drops of distilled water were put on different zones along the pellet surface area to calculate the filtration time as a function of droplet locations on the pellet. The distance is considered from the edge of the pellet. The goal was to analyze the filtration parameters as a function of the homogeneity of the surface and particularly to compare the edge of the pellet with the central part.

The analysis of SEM images of the surface and the cross-section of the pellets between the edge and the center allows to compare the distribution of pores for the different samples but not the homogeneity of the material and particularly the boundaries of the pellet. In this experiment, distillated water droplets were put in different places along the surface area of the sample to measure the filtration time until the complete saturation of the porous sample as a function of the location where we put the droplet on the sample. At the end of each diffusion of droplets the diameter of the diffused liquid was measured at the location where the liquid has reached the other pellet's side. A syringe was set above the sample, and successive drops of distilled water were deposited on the surface and observed with the imaging system. Each volume of drops is $0.02 \mathrm{ml}$. Successive droplets are put on the surface until the effect of the droplet diffusion appears on the lower side of the sample. The time for observing the liquid on the back surface is measured and plotted in the figure 7 for the different samples.

The measurements have confirmed that the spread of the fluid varies as a function of the different locations on the sample and therefore it confirms that the spatial distribution of pores in the samples is nonhomogeneous and an edge effect is observed (fig.7). We observe that the slope of the curve is negative for all the samples except DD3Z meaning that the conditions of liquid flows are different between the center and the edge of the pellet with probably a porosity and a tortuosity effect different. Moreover, for DD3Z(t) the homogeneity varies differently. The pellet is less compact close to the edge than at the center for this material. We can also see that some samples have a greater capacity to store different volumes. The parameters obtained by a surface and a cross-section analyze are not fully suitable parameters to describe all the hydrodynamic behaviors and to predict the permeability of the whole bulk of pellets. Average pore sizes, average pore throat sizes and average throat lengths extracted from 2D images are not homogeneous in the bulk and a ratio of 6 could be expected. All the samples except DD3Z(t) are compact at the center and the time to reach the saturation is longer than on the edge. For $\operatorname{DD} 3 Z(t)$ material it is faster to diffuse the liquid on the edge than at the center. So, edge effects 
can occur in the fabrication of pellets and larger diameter of pellets are requested to avoid such effects and to guarantee a better homogeneity.

\subsection{Time-dependent fluid flow}

In a second experiment we have measured the time-dependent position of the visible wetted front at it moved through the cross-section of the pellet for the four different samples with timelapse videos. We observed in the figure 8 that the results of the hydrodynamic flow agree with the expected results obtained with the suitable parameters measured with SEM images (pore radius, connectivity, porosity ratio, ...). All the time dependent liquid position measurements can be plotted in logarithmic scale and we can observe the quadratic dependence of the penetration depth as a function of time. The obtained results can well be fitted with a LucasWashburn like curve [34 - 36] $\left(\mathrm{L}^{2}=\mathrm{Bt}\right)$ with $\mathrm{B}=9.51,1.73,5.57,9.74$ for DD3Z(t), DD3Z(t) $+37 \% \mathrm{Zn}, \mathrm{DD} 3 \mathrm{Z}(\mathrm{t})+50 \% \mathrm{ZnO}, \mathrm{DD} 3 \mathrm{Z}(\mathrm{t})+50 \% \mathrm{Mg}$ respectively. This equation refers to a steady process, where the capillary force is compensated by gravity and viscous drag. B is a dimensionless permeability coefficient of the material. The coefficient accounts for the tortuosity of the flow path, the porosity of the material and the lengths of the pores. The flow of the liquid is generated by a negative pressure which pulls the fluid toward unwetted regions of the doped DD3 material. The liquid sucked into the porous material is accelerated by capillary force and soon thereafter the capillary force is compensated by the viscous drag so that a quasi-steady state is achieved.

The Lucas-Washburn equation can be written as:

$$
\mathrm{L}^{2}=\frac{D \cdot \gamma \cdot \cos \theta}{4 \eta} \mathrm{t}
$$

where $t$ is the time for a liquid of dynamic viscosity $\eta$ and surface tension $\gamma$ to penetrate a distance $L$ into the capillary whose pore diameter is $D$ and $\theta$ the contact angle between the liquid and the sample surface. For water, $\eta=1.10^{-3} \mathrm{~kg} / \mathrm{m} . \mathrm{s}, \gamma=7310^{-3} \mathrm{~N} / \mathrm{m}$. The contact angles are $\theta=20.5^{\circ}, 16^{\circ}, 25.1^{\circ}, 34.5^{\circ}$ for DD3Z(t), DD3Z(t) $+37 \% \mathrm{ZnO}, \mathrm{DD} 3 \mathrm{Z}(\mathrm{t})+50 \% \mathrm{ZnO}$, $\mathrm{DD} 3 \mathrm{Z}(\mathrm{t})+50 \% \mathrm{Mg}$ respectively.

DD3Z is the material with a high penetration depth contrary to DD3Z(t) $+37 \% \mathrm{ZnO}$ which has a very low penetration depth due to a very small porosity ratio and an average pore radius. We point out that $\mathrm{DD} 3 \mathrm{Z}(\mathrm{t})+50 \% \mathrm{Mg}$ has a very fast penetration depth and reach a saturation faster which is confirmed by the logarithm plot due to low porosity ratio and a small average pore 
radius but with a high coordination number and a high average throat length. This measure confirms that these two parameters are very important for the permeability in porous materials. We can observe that for all the materials there is an oscillatory regime in the height around the equilibrium position, as it has been largely discussed in [37]. This effect is due to the low viscosity of the liquid. It was demonstrated that a wetting liquid put in contact with a tube indefinitely oscillates in this tube (transforming surface energy in kinetic and gravitational energies [38].

The limit in time of the linear regime and the time of the quasi-state is different for the four materials and we see that for DD3Z(t) $+50 \% \mathrm{Mg}$ this limit occurs quickly. This limit occurs at a time $\gamma D^{2} / 4 \eta$ which can be physically understood as the time necessary for the viscous boundary layer to diffuse on a length of order fixed by the porosity parameters of the materials. The viscous drag can induce damping oscillations. The amplitude of capillary oscillations decreases with the capillary lengths as it shown for DD3Z(t) $+37 \% \mathrm{ZnO}$ and DD3Z.The figure 8 shows that the important effect of penetration depth as a function of the time can be connected to the important role of the open porosity with the different doping. The maximum time for penetration of a water droplet is reached for DD3Z(t) $+50 \% \mathrm{Mg}$. DD3Z(t) $+50 \% \mathrm{ZnO}$ and $\mathrm{DD} 3 \mathrm{Z}(\mathrm{t})+50 \% \mathrm{Mg}$ seems the best material with a compromise between the penetration depth and the time for the hydrodynamic flow or permeability. Improvements in photoactivity are influenced by the template dimension, which correlates to the pore parameters of the studied material [39].

A test has been done to measure the maximum number of droplets before liquid saturation of the pellet. A number of droplets of 75 has been drop off corresponding to $1.1 \mathrm{ml}$. DD3Z(t) + $50 \% \mathrm{ZnO}$ is the fastest with the same volume of water before saturation. This saturation effect cannot be deduced with the measured parameters obtained with the SEM images of the surface. The figure 9 confirms the differences between the doped materials. In the experiment we measured the number of drops before a complete saturation. We define the saturation as the moment where the liquid appears on the other face of the pellet. We measured the number of drops for reaching this observation. DD3Z(t) $+50 \% \mathrm{Mg}$ is the fastest material reaching this state. The saturation occurs quickly due to the large pore coordination number and pore throat. $\mathrm{DD} 3 \mathrm{Z}(\mathrm{t})+50 \% \mathrm{ZnO}$ is the longest to reach saturation because of a low pore coordination number and a small pore throat even if the pore radius is big compare to the other materials. 


\section{Conclusions}

Different types of pellets based on ceramics (mullite -zircon) and zinc /magnesium prepared by a co-precipitation method were studied. The SEM results show the structure of these pellets and the changes in composition, explained by an increase of the open porosity especially with the addition of zinc (type DD3Z(t) $+50 \% \mathrm{ZnO}$ ). The characteristics of the materials (porosity, chord length, pore throat) have been calculated. In order to confirm the influence of the materials on the porosity, the samples were studied with water. DD3Z(t) $+50 \% \mathrm{Mg}$ is the material with the faster permeability confirmed by the high speed for liquid saturation and DD3Z $(\mathrm{t})+37 \% \mathrm{ZnO}$ the slower. The method proposed allows to determine the general conditions of liquid penetration inside the ceramic sample by considering local and non-local parameters.

\section{Acknowledgment}

This work has been supported by the Laboratory of Active Components and Materials (LACM) of Larbi Ben M'hidi University - Oum El Bouaghi, Algeria and the laboratory of MOLTECHAnjou, University of Angers, France. 


\section{References}

[1] S. Mahesh Kumar, G. M. Madhu, R. Sukumar, Fouling behaviour, regeneration options and on-line control of biomass-based power plant effluents using micro porous ceramic membranes, Separation and Purification Techn. 57 (2007) 25-36, https://doi.org/10.1016/j.seppur.2007.03.002.

[2] S. Vercauteren, K. Keizer, E. F. Vansant. J. Luyten. R. Leysen, Porous Ceramic Membranes: Preparation, Transport Properties and Applications, J. of Porous Mater. 5 (3 - 4) (1998) 241-258, https://doi.org/10.1023/A:1009634305315.

[3] L. Zhu, Y. Dong, S. Hampshire, S. Cerneaux, L. Winnubst, Waste-to-resource preparation of a porous ceramic membrane support featuring elongated mullite whiskers with enhanced porosity and permeance, J. of the Eur. Ceramic Soc. 35 (2015) 711-721, https://doi.org/10.1016/j.jeurceramsoc.2014.09.016.

[4] E. McLeary, J. Jansen, F. Kapteijn, Zeolite based films, membranes and membrane reactors: Progress and prospects, Microporous and mesoporous materials 90 (2006) 198-220, https://doi.org/10.1016/j.micromeso.2005.10.050.

[5] R. Weber, H. Chmiel, V. Mavrov, Characteristics and application of new ceramic nanofiltration membranes, Desalination 157 (2003) 113-125, https://doi.org/10.1016/S00119164(03)00390-4.

[6] T. Tsuru, T. Sudoh, T. Yoshioka, M. Asaeda, Nanofiltration in non-aqueous solutions by porous silica -zirconia membranes, J. of Membrane Sci. 185 (2001) 253-261, https://doi.org/10.1016/S0376-7388(00)00651-7.

[7] Y. Elmarraki, M. Cretin, M. Persin, J. Sarrazin, A. Larbot, Elaboration and properties of $\mathrm{TiO}_{2}-\mathrm{ZnAl}_{2} \mathrm{O}_{4}$ ultrafiltration membranes, Mater. Research Bull. 36 (2001) 227-237, https://doi.org/10.1016/j.proeng.2012.01.1205.

[8] M. D. Afonso, R. Bórquez, Review of the treatment of seafood processing wastewaters and recovery of proteins therein by membrane separation processes-prospects of the ultrafiltration of wastewaters from the fish meal industry, Desalination 142 (2002) 29-45, https://doi.org/10.1016/S0011-9164(01)00423-4.

[9] C. Song, T. Wang, Y. Pan, J. Qiu, Preparation of coal-based microfiltration carbon membrane and application in oily wastewater treatment, Separation and purification technology 51 (2006) 80-84, https://doi.org/10.1016/j.seppur.2005.12.026. 
[10] C. Brandes, L. Treccani, S. Kroll, K. Rezwan, Gel Casting of Free-Shapeable Ceramic Membranes with Adjustable Pore Size for Ultra- and Microfiltration, J. of the Am. Ceramic Soc. 97 (2014) 1393- 1401, https://doi.org/10.1111/jace.12877.

[11] S. Bouzid Rekik, J. Bouaziz, A. Deratani, S. Baklouti, Study of Ceramic Membrane from Naturally Occurring-Kaolin Clays for Microfiltration Applications, Periodica Polytechnica Chemical Engineering 61(2017) 206-215, http://dx.doi.org/10.3311/PPch.9679.

[12] J. Cao, X. Dong, L. Li, Y. Dong, S. Hampshire, Recycling of waste fly ash for production of porous mullite ceramic membrane supports with increased porosity, J. of the Eur. Ceramic Soc. 34 (2014) 3181-3194, https://doi.org/10.1016/j.jeurceramsoc.2014.04.011.

[13] S. Fakhfakh, S. Baklouti, S. Baklouti, J. Bouaziz, Elaboration and characterization of low cost ceramic support membrane, Adv. in Appl. Ceramics 108 (2010) 31-38, https://doi.org/10.1179/174367609X422234.

[14] S. Rekik, J. Bouaziz, A. Deratani, S. Baklouti, Development of an asymmetric ultrafiltration membrane from naturally occurring kaolin clays: Application to the cuttlefish effluents treatments, Int. J. of Membrane Sci. and Tech. 6 (2016) 1000159, 10.4172/21559589.1000159 .

[15] M. Ebrahimi, KS. Ashaghi, L. Engel, D. Willershausen, P. Mund, P. Bolduan, P. Czermak, Characterization and application of different ceramic membranes for the oil -field produced water treatment, Desalination 245 (2009) 533-540, https://doi.org/10.1016/j.desal.2009.02.017. [16] A. Mecif, J. Soro, A. Harabi, and J. P. Bonnet, Preparation of Mullite- and Zircon-Based Ceramics Using Kaolinite and Zirconium Oxide: A Sintering Study, J. of the Am. Ceramic Soc. 93 (2010) 1306-1312, https://doi.org/10.1111/j.1551-2916.2009.03595.x.

[17] D. Bouras, A. Mecif, A. Mahdjoub, A. Harabi, M. Zaabat, S. Benzitouni, R. Barille, Photocatalytic degradation of orange II by active layers of cu-doped $\mathrm{ZnO}$ deposited on porous ceramic Substrates, J. of Ovonic Research 13 (2017) 271-281.

[18] D. Bouras, A. Mecif, R. Barille, A. Harabi, M. Rasheed, A. Mahdjoub, M. Zaabat, Cu:ZnO deposited on porous ceramic substrates by a simple thermal method for photocatalytic application, Ceramics internation. 44(17) (2018), 21546-21555, https://doi.org/10.1016/j.ceramint.2018.08.218.

[19] A. Kucharczyk, K. Naplocha, J. W. Kaczmar, K. U. Kainer, Current Status and Recent Developments in Porous Magnesium Fabrication, Adv. Eng. Mater. 20 (2018) 1700562, https://doi.org/10.1002/adem.201700562.

[20] P. J. Gosting, L. J. Kegeles, G. Flow, equations and frames of reference for isothermal diffusion in liquids, J. of Chem. Phys. 33 (2004) 1505-1513, https://doi.org/10.1063/1.1731433. 
[21] F. A. L. Dullien, Porous Media: Fluid Transport and Pore Structure, second ed., Academic Press, San Diego, 1992.

[22] H. Senoussi, H. Osmani, C. Courtois, M. H. Bourahli, Mineralogical and chemical characterization of DD3 kaolin from the east of Algeria, boletín de la sociedad española de cerámica y vidrio 55 (2016) 121-126, https://doi.org/10.1016/j.bsecv.2015.12.001.

[23] M. Ashokkumar, S. Muthukumaran, Microstructure optical and FTIR studies of Ni, Cu codoped ZnO nanoparticles by co-precipitation method, Opt. Mater. 37 (2014) 671-678, https://doi.org/10.1016/j.optmat.2014.08.012.

[24] H. Senoussia, H. Osmania, C. Courtoisb, M. el Hadi Bourahli, Mineralogical and chemical characterization of DD3 kaolin from the east of Algeria, boletin de la sociedad espanola de ceramica y vidrio, 55 (2 0 l 6) 121-126, https://doi.org/10.1016/j.bsecv.2015.12.001

[25] D. M. Turner, S. R. Niezgoda, S. R. Kalidindi, Efficient computation of the angularly resolved chord length distributions and lineal path functions in large microstructure datasets

Modelling Simul. Mater. Sci. Eng. 24 (2016) 075002, https://doi.org/10.1088/09650393/24/7/075002.

[26] A. Rabbani, S. Jamshidi, S. Salehi, An automated simple algorithm for realistic pore network extraction from micro-tomography images, J. of Petroleum Sci. and Eng. 123 (2014) 164 - 171, https://doi.org/10.1016/j.petrol.2014.08.020.

[27] A. Rabbani, S. Ayatollahi, R. Kharrat, N. Dashti, Estimation of 3-D pore network coordination number of rocks from watershed segmentation of a single 2-D image, Adv. in water resources, 94 (2016) 264-277, https://doi.org/10.1016/j.advwatres.2016.05.020.

[28] S. - C. Chen, E. K. C. Lee, Y.- I. Chang, Effect of the coordination number of the porenetwork on the transport and deposition of particles in porous media, Separation and Purification Technology 30 (2003) 11-26, https://doi.org/10.1016/S1383-5866(02)00096-5.

[29] A. Encalada, J. Barzola-Monteses, M. Espinoza-Andaluz, A Permeability-Throat Diameter Correlation for a Medium Generated with Delaunay Tessellation and Voronoi Algorithm Transport in Porous Media 132, (2020) 201-217, https://doi.org/10.1007/s11242020-01387-z

[30] P.M. Radingoana, S. Guillemet-Fritsch, P.A. Olubambi, G. Chevalliet, C. Estournès, Influence of processing parameters on the densification and the microstructure of pure zinc oxide ceramics prepared by spark plasma sintering, (2019) Ceramics International, 45 (8) 10035-10043, https://doi.org/10.1016/j.ceramint.2019.02.048 
[31] B. M. Cummins, R. Chinthapatla, F. S. Ligler, G. M. Walker, Time-Dependent Model for Fluid Flow in Porous Materials with Multiple Pore Sizes, Anal. Chem., 89 (2017) 4377-4381, https://doi.org/10.1021/acs.analchem.6b04717.

[32] H. Bayesteha, A. A. Mirghasemi, Numerical simulation of porosity and tortuosity effect on the permeability in clay: Microstructural approach, Soils and Foundations, 55(5) (2015) 1158-1170. https://doi.org/10.1016/j.sandf.2015.09.016.

[33] A. Rabbania, A. Assadib, R. Kharrata, N. Dashtia, S. Ayatollahi, Estimation of carbonates permeability using pore network parameters extracted from thin section images and comparison with experimental data, J. of Natural Gas Sci. and Eng. 42 (2017) 85-98, https://doi.org/10.1016/j.jngse.2017.02.045.

[34] E. W. Washburn, The dynamic of capillary flow, Phys. Rev. 17 (1921) 273 - 283, https://doi.org/10.1103/PhysRev.17.273.

[35] A. Hamraoui, T. Nylander, Analytical Approach for the Lucas-Washburn Equation, J. of Colloid and Interface Sci. 250 (2002) 415-421, https://doi.org/10.1006/jcis.2002.8288.

[36] B. V. Zhmud, F. Tiberg, K. Hallstensson, Dynamics of Capillary Rise, J. of Colloid and Interface Sci. 228 (2000) 263-269, https://doi.org/10.1006/jcis.2000.6951.

[37] D. Quere, E. Raphael, Rebounds in a Capillary Tub, Langmuir 15 (1999) 3679-3682, https://doi.org/10.1021/la9801615

[38] M. -H. Sun, S. -Z. Huang, L. - H. Chen, Y. Li, X. - Y. Yang, Z.-Y. Yuan B. -L. Su, Applications of hierarchically structured porous materials from energy storage and conversion, catalysis, photocatalysis, adsorption, separation, and sensing to biomedicine, Chem. Soc. Rev. 45 (2016) 3479 - 3563, https://doi.org/10.1039/C6CS00135A.

[39] R. Nisticò, The importance of surfaces and interfaces in clays for water remediation processes, Surf. Topogr.: Metrol. Prop. (2018) 6 043001, https://doi.org/10.1088/2051672X/aaed09. 


\section{Tables}

Table.1. parameters of the samples measured with surface and cross-section images of the pellets

\begin{tabular}{|l|l|l|l|l|}
\hline Pellets & $\begin{array}{c}\text { Porosity } \\
\text { ratio } \\
{[\%]}\end{array}$ & $\begin{array}{l}\text { Coordination } \\
\text { number }\end{array}$ & $\begin{array}{c}\text { Average } \\
\text { throat } \\
\text { radius [nm] }\end{array}$ & $\begin{array}{c}\text { Pore } \\
\text { radius } \\
{[\mathbf{n m}]}\end{array}$ \\
\hline $\mathrm{DD} 3 \mathrm{Z}(\mathrm{t})$ & 20 & 4.8 & 702 & 59 \\
\hline $\mathrm{DD} 3 \mathrm{Z}(\mathrm{t})+37 \% \mathrm{ZnO}$ & 18 & 4.9 & 820 & 47 \\
\hline $\mathrm{DD} 3 \mathrm{Z}(\mathrm{t})+50 \% \mathrm{ZnO}$ & 26 & 4.7 & 702 & 80 \\
\hline $\mathrm{DD} 3 \mathrm{Z}(\mathrm{t})+50 \% \mathrm{Mg}$ & 16 & 5.0 & 1050 & 46 \\
\hline
\end{tabular}




\section{Figure captions}

Figure1: The step by step method for the preparation of pellets of ceramic based materials with a mixture of mullite and zircon on the top and strengthened by the addition of zinc and magnesium sorbents at different rates.

Figure 2: Analysis of XRD diagrams of the different materials with $2 \theta$ from $15^{\circ}$ to $45^{\circ}$. (M) mullite, (Zr) $\mathrm{ZrO}$ 2, (ZrS), $\mathrm{ZrSiO} 4,(\mathrm{C})$ cristobalite and ( $\mathrm{ZO}) \mathrm{ZnO}$. The mineralogical and chemical characteristics of the raw material known as DD3, from eastern Algeria could be found in [16] and [24].

Figure 3: Set-up for the characterization of the liquid diffusion into the ceramic samples.

Figure 4: SEM images of DD3Z(t) (a), DD3Z(t)+37\%Zn (b), DD3Z(t)+50\%Zn (c) and $\operatorname{DD} 3 Z(t)+50 \% \mathrm{Mg}(\mathrm{d})$ with the corresponding calculated porosity network.

Figure 5: Chord length distribution for each sample with the corresponding superposition of the fitting curves. All the fitting curves are superposed for comparison.

Figure 6: Representation of the pore throat for the different samples with $\operatorname{DD} 3 Z(t)(a)$, DD3Z(t)+37\%Zn (b), DD3Z(t)+50\%Zn (c) and DD3Z(t)+50\%Mg (d).

Figure 7: Measured time of water droplet diffusion into the sample for different positions of the drop on the pellet.

Figure 8: Permeability of the different samples with the penetration depth measurements of water as a function of time in a linear scale.

Figure 9: Time required for a complete saturation of water into the different samples measured with the number of drops until saturation. 


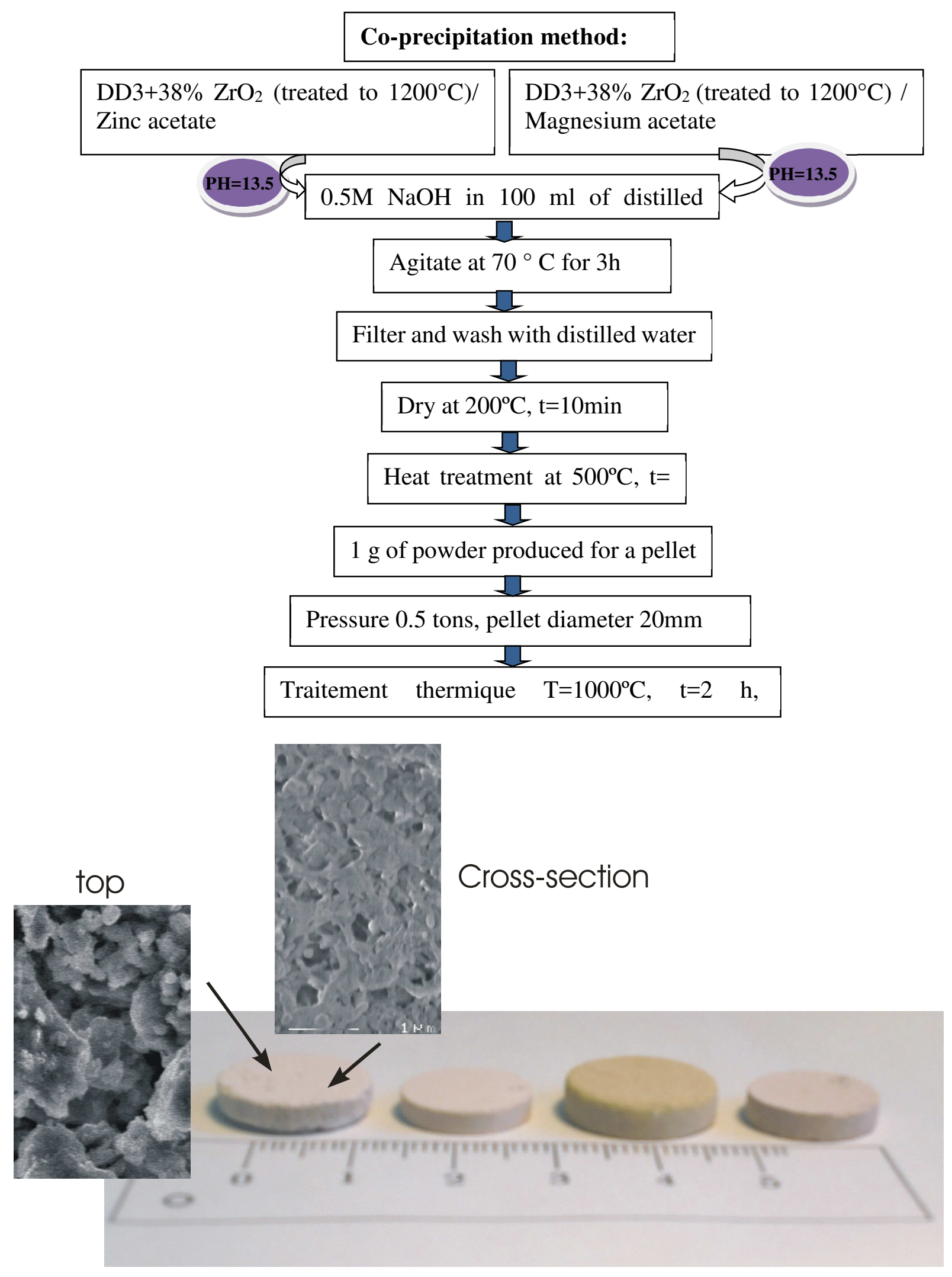

Figure 1 


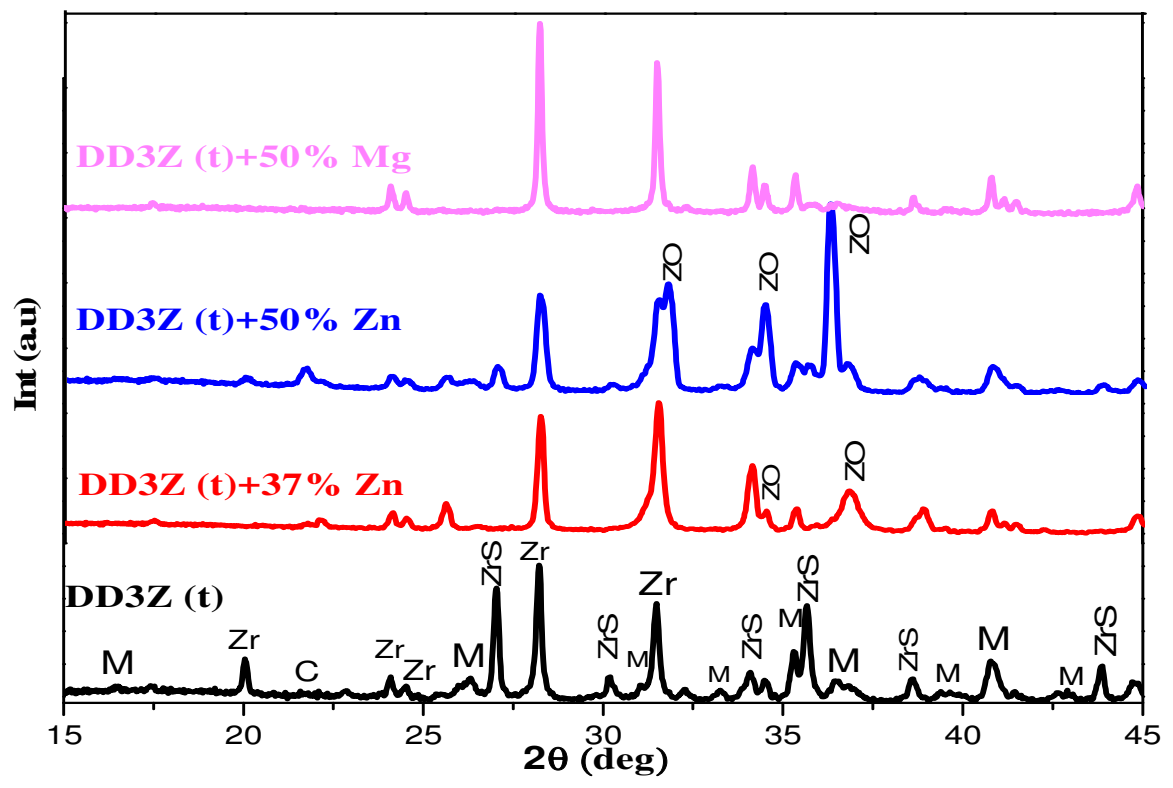

Figure 2 


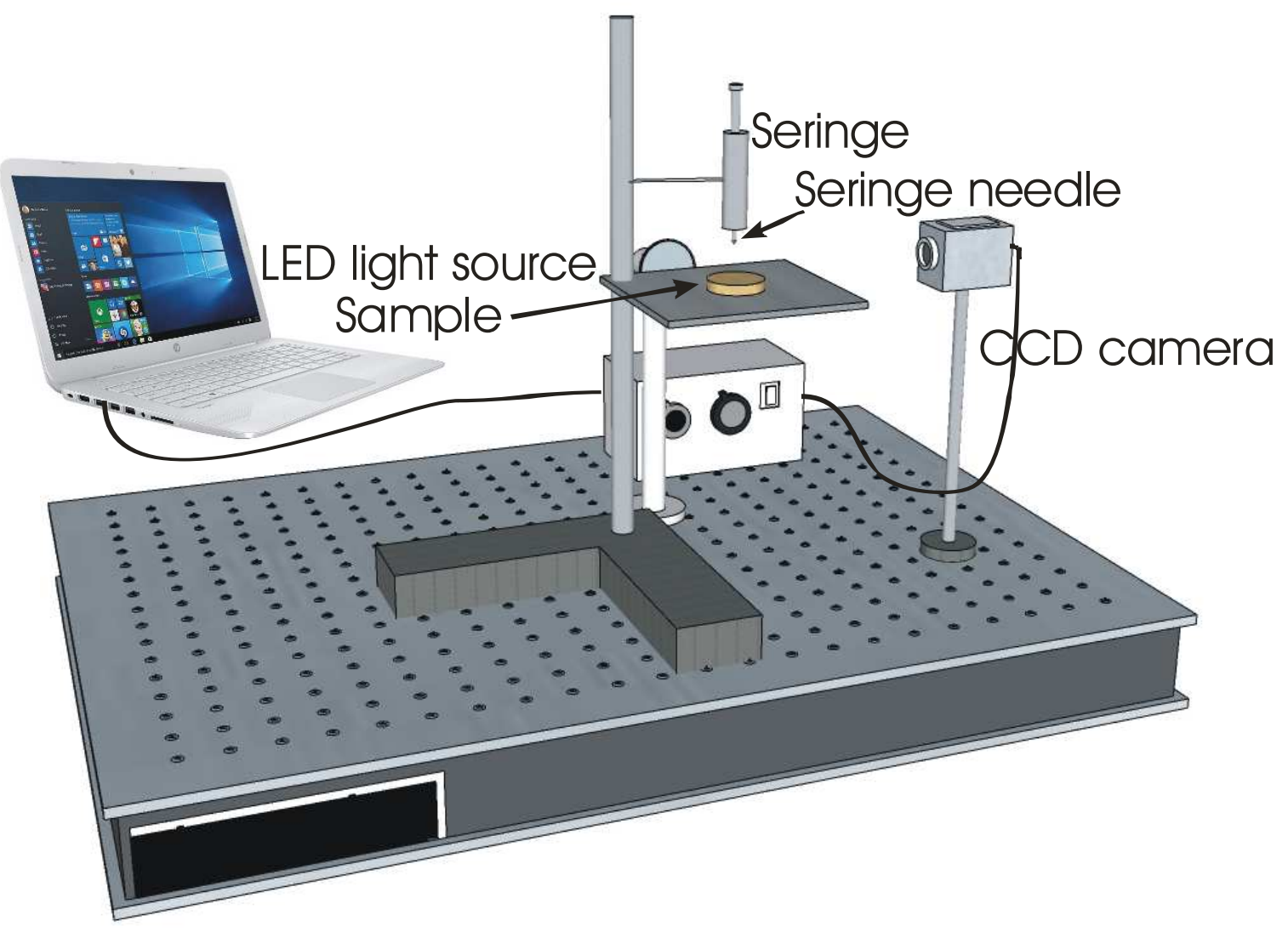

Figure 3 


\section{SEM image}
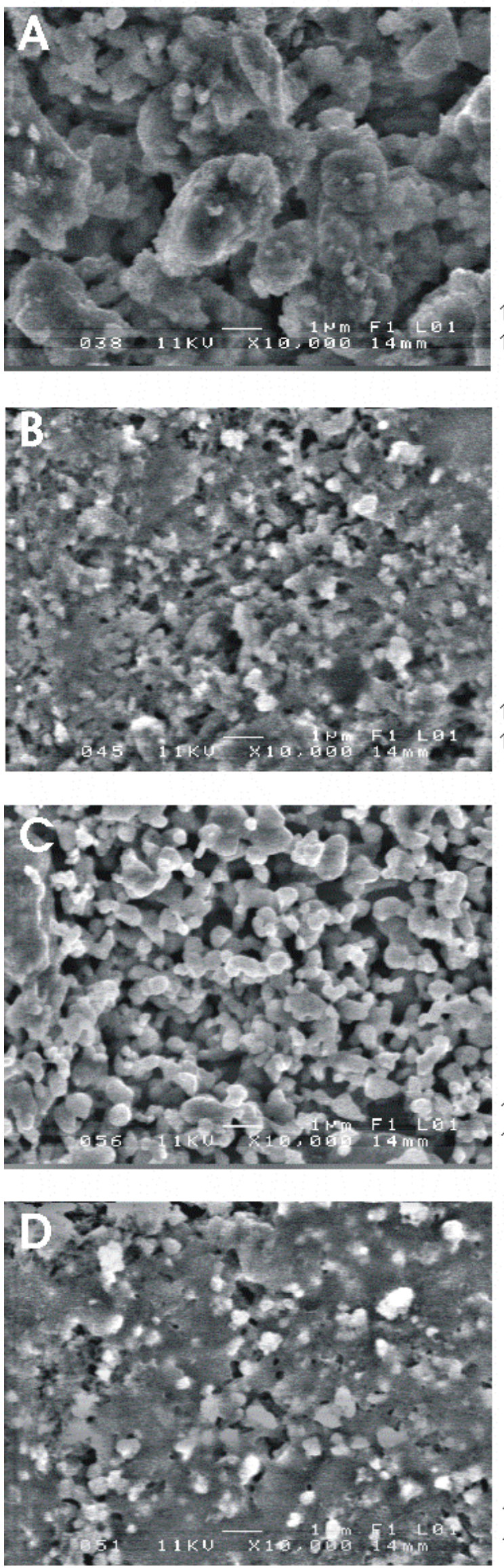

\section{Porosity}

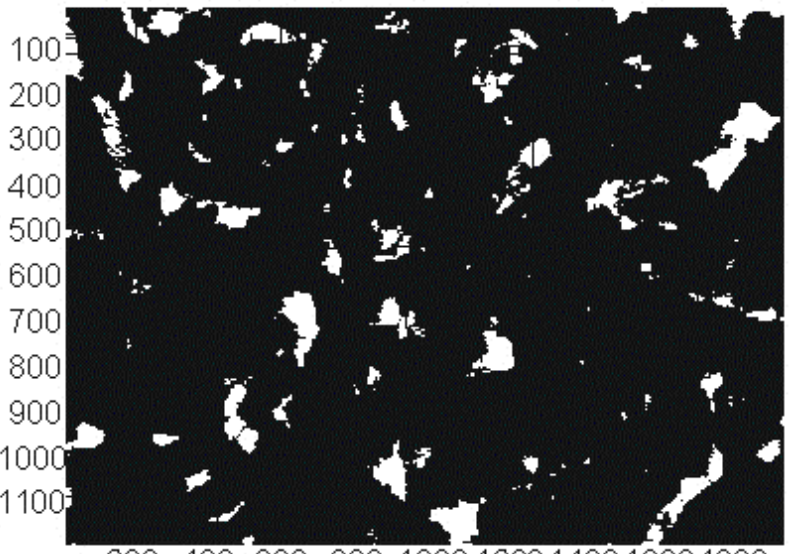

20040060080010001200140016001800
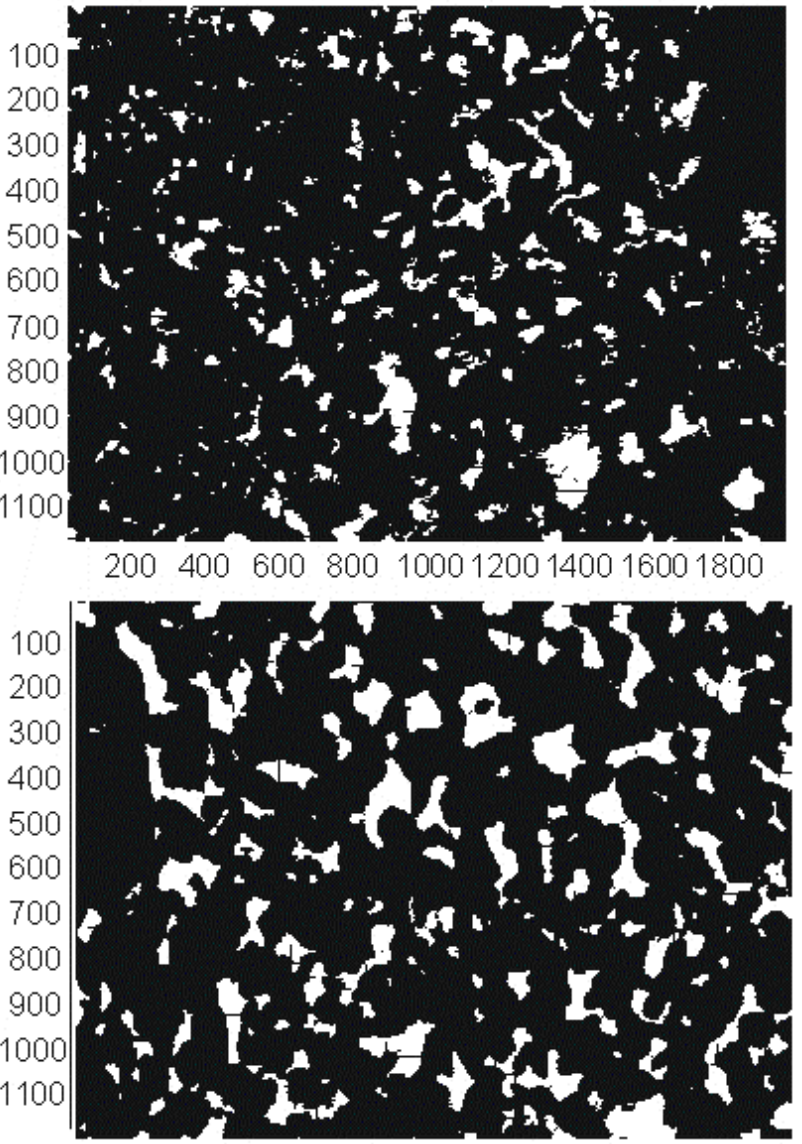

20040060080010001200140016001800

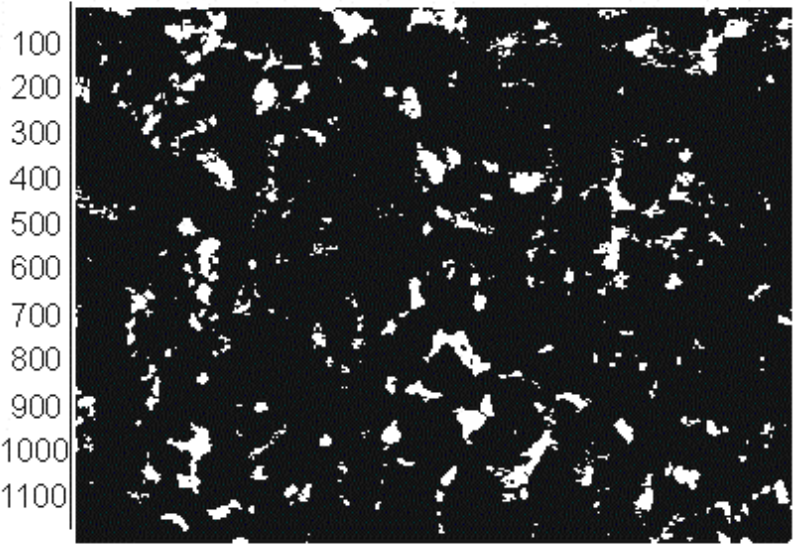

20040060080010001200140016001800 
Figure 4
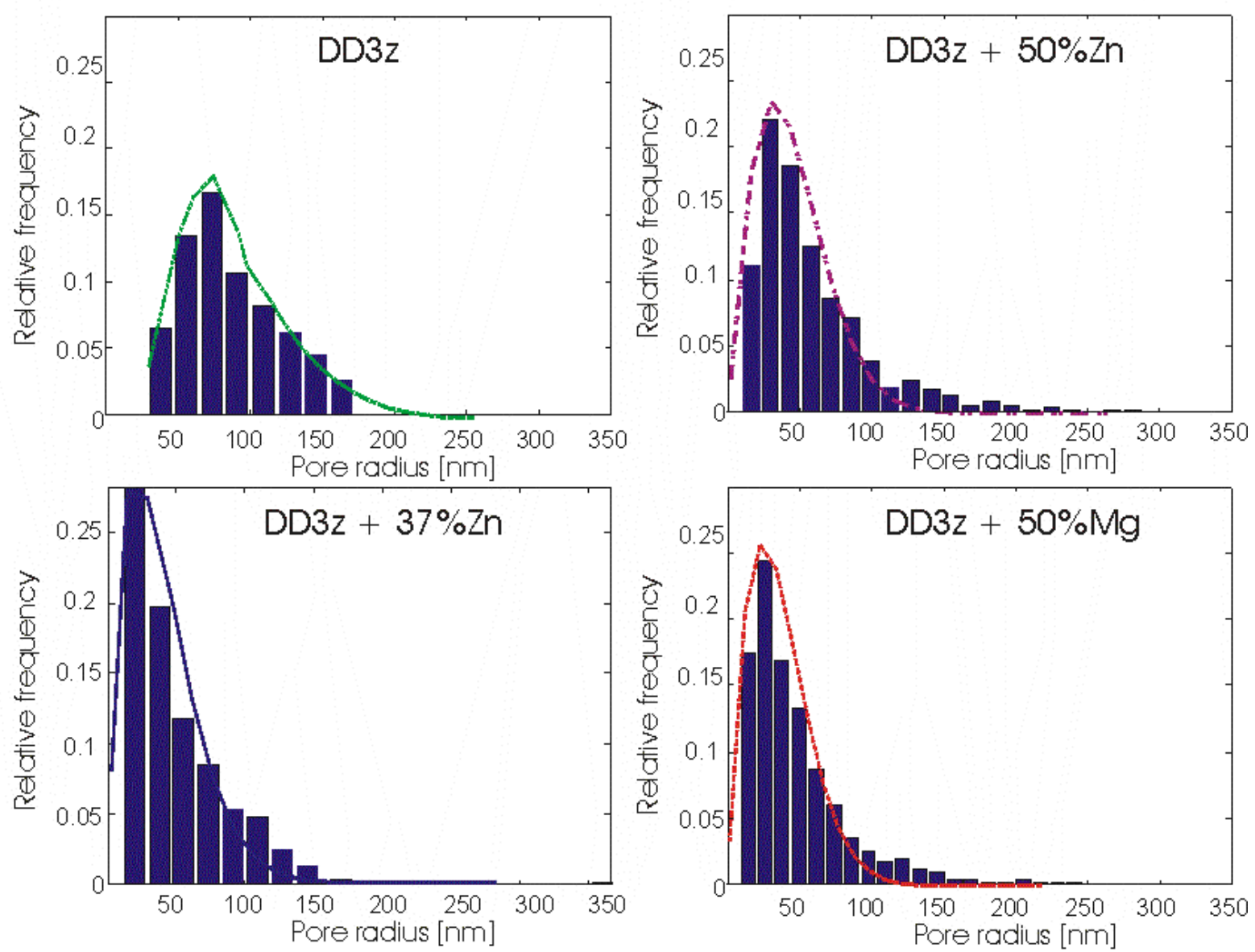

Figure 5 

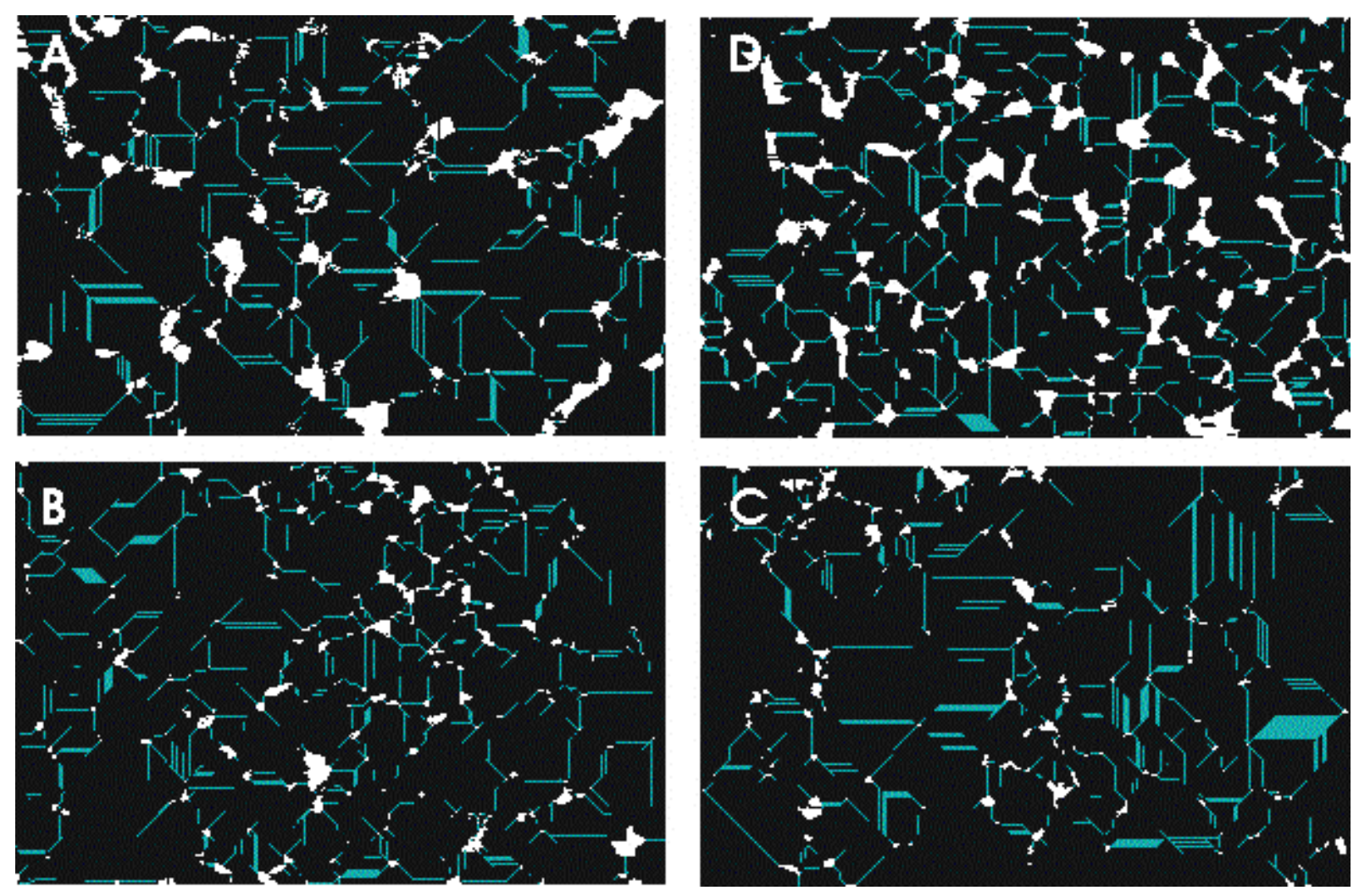

Figure 6 

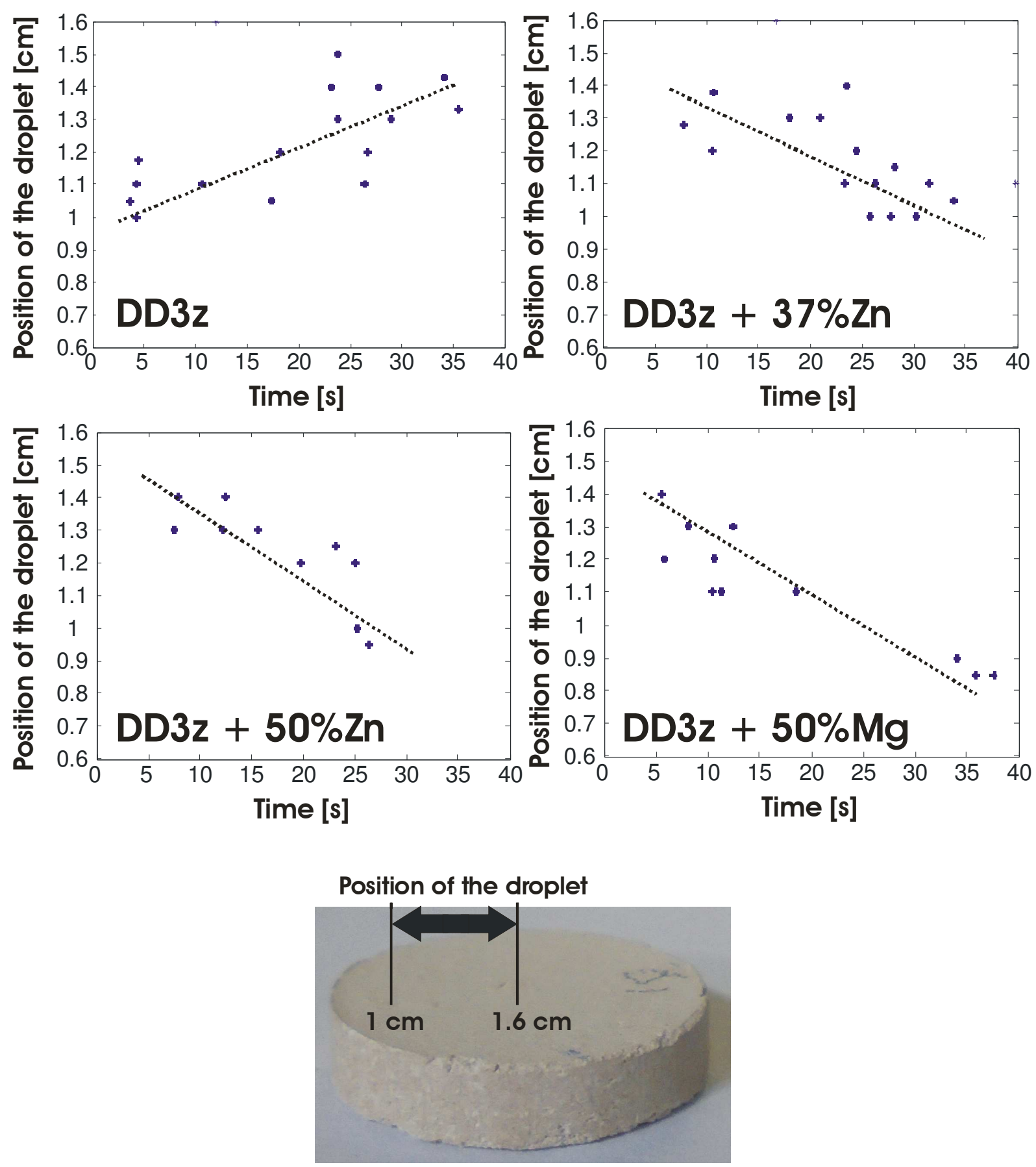

Figure 7 


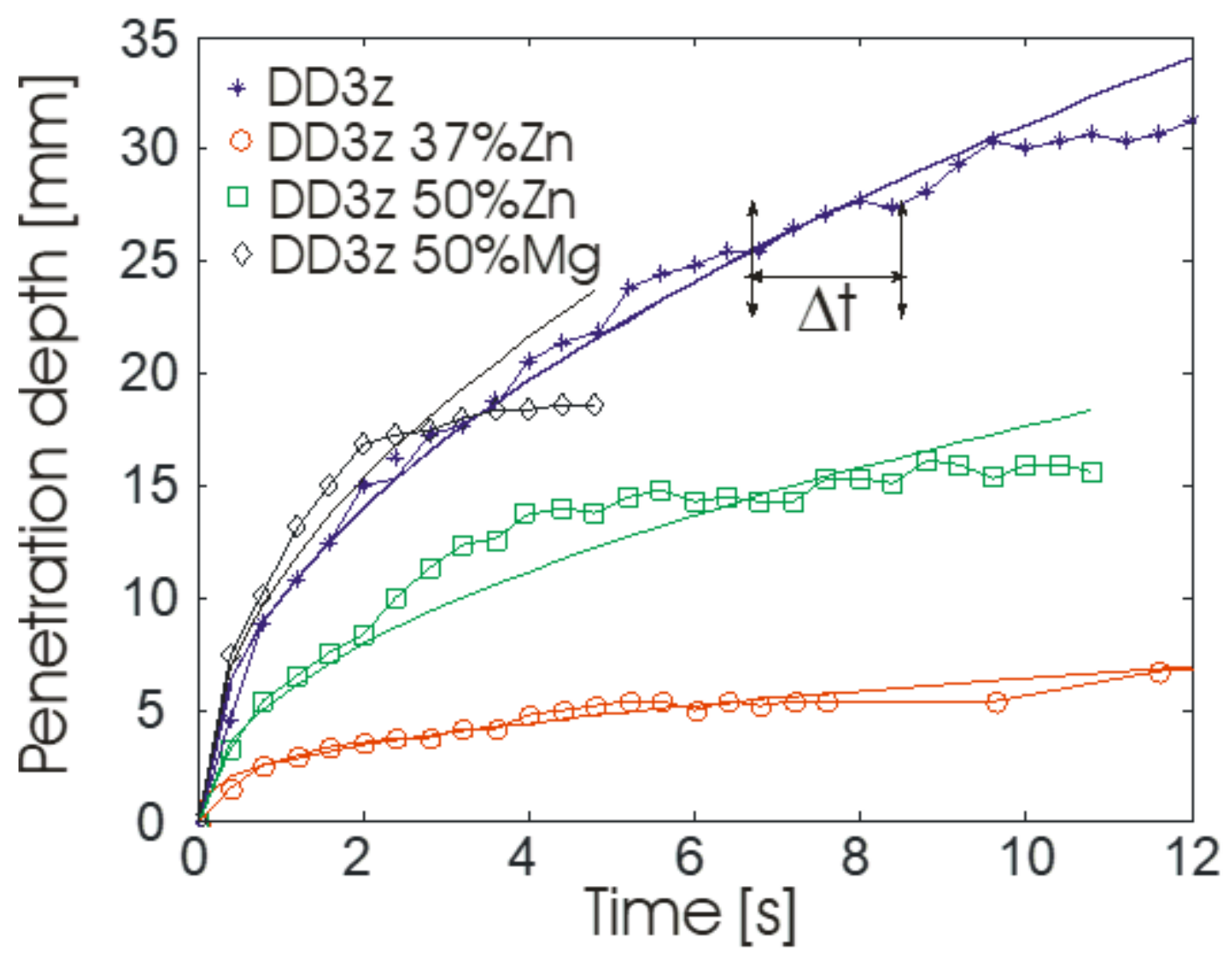

Figure 8 


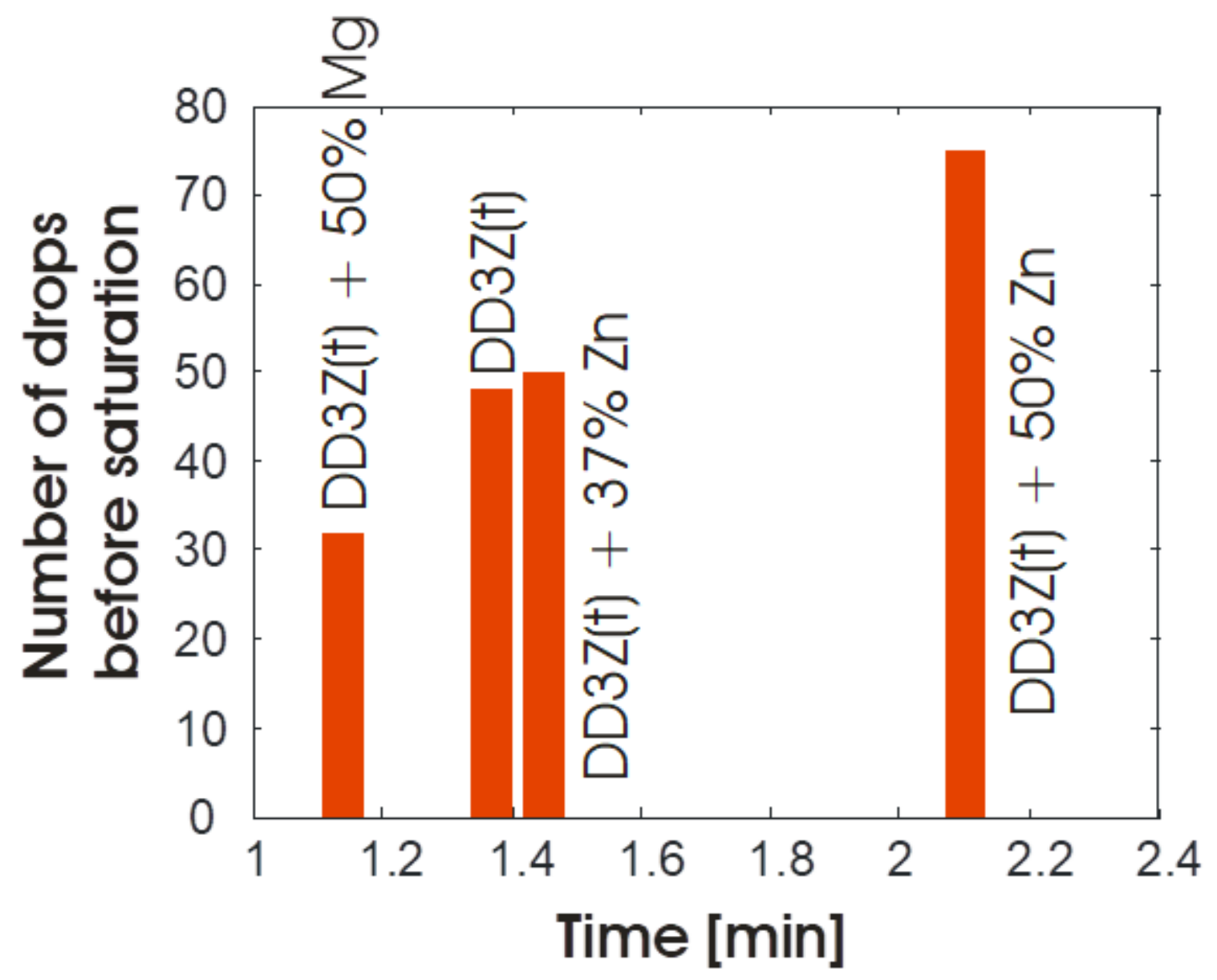

Figure 9 